\title{
Geometric morphometrics of Aedes aegypti populations and study of transmission of arboviral diseases in Barreiras, Brazil
}

\author{
Danielle Beatriz Marques Campos Arcanjo ${ }^{1}$, Paloma Oliveira Vidal ${ }^{1}$, \\ José Yure Gomes dos Santos ${ }^{2}$, Larissa Paola Rodrigues Venancio ${ }^{1}$, \\ Lincoln Suesdek ${ }^{3,4}$, Jaime Henrique Amorim ${ }^{1 *}$ [) \\ ${ }^{1}$ Universidade Federal do Oeste da Bahia, Centro das Ciências Biológicas e da Saúde, Laboratório de Agentes Infecciosos e Vetores, \\ Barreiras, BA, Brasil. \\ ${ }^{2}$ Universidade Federal do Oeste da Bahia, Centro das Humanidades, Laboratório de Geoprocessamento, Barreiras, BA, Brasil. \\ ${ }^{3}$ Instituto Butantan, Laboratório de Parasitologia, São Paulo, SP, Brasil. \\ ${ }^{4}$ Universidade de São Paulo, Instituto de Medicina Tropical, São Paulo, SP, Brasil.
}

\section{A R T I C L E I N F O}

Article history:

Received 18 June 2019

Accepted 17 December 2019

Available online 14 February 2020

Associate Editor: Mario Navarro Silva

\section{Keywords:}

A.aegypti

geometric morphometrics

transmission

barriers

segregation

\begin{abstract}
A B S T R A C T
Aedes (Stegomyia) aegypti $(A$. aegypti) transmits arboviral diseases of high public health importance, including those caused by Zika virus (ZIKV), Dengue virus (DENV), Chikungunya virus (CHIKV) and Yellow fever virus (YFV). Barreiras is a city with 157,638 inhabitants in the West of the State of Bahia, Northeast of Brazil. The climate is dry, with well-determined and concentrated seasons of rains. The city is crossed by a Federal Highway and by the Rio Grande river. In this study, we aimed to understand the dynamics of mosquito vectors and arboviral diseases in Barreiras. We used correlation statistics to investigate a possible relationship among rains, mosquito abundance and transmission of diseases. In addition, as a preliminary population genetics estimate, we used geometric morphometrics to compare mosquitoes from areas limited by a highway and a river. We found that i) infestation occurs in rain-dependent cycles and that ii) both, the river and the highway segregate populations of $A$. aegypti in different areas of the studied city. Our results indicate that it is necessary to treat anthropic containers with mosquito breading capacity during both, the dry and rain seasons in urban areas similar to Barreiras.
\end{abstract}

\section{Introduction}

Aedes (Stegomyia) aegypti (A. aegypti) transmits arboviral diseases of high public health importance, including those caused by Zika virus (ZIKV), Dengue virus (DENV) and Yellow fever virus (YFV) ("Transmission |Zika virus |CDC,"). Such mosquito vector is well adapted to urban areas. In addition, eggs of $A$. aegypti mosquitoes are resistant to desiccation (Hemme et al., 2010). Thus, they have a high capacity to be passively spread to new areas via human transportation networks (Soper, 1967; Pongsumpun et al., 2008). Although vaccines are available to control some arboviral diseases, control programs rely mainly on the suppression of vector populations to prevent human exposure to infected mosquitoes. In this context, understanding the distribution and variability of mosquito vectors in a given city is necessary to design efficient programs of surveillance and control.

\footnotetext{
* Corresponding author.

E-mail: jaime.amorim@ufob.edu.br (J.H. Amorim)
}

Barreiras is a city with 157,638 inhabitants in the West of the State of Bahia, in the Northeast of Brazil. The city has a dry climate, with well-determined and concentrated seasons of rains. The city is crossed by a Federal Highway and by the Rio Grande river. Until the present, only the municipal Epidemiological Surveillance have raised information regarding arboviral diseases epidemics and vectors in Barreiras. As far as we know, there are not published scientific studies showing the distribution and variability of mosquitoes vectors in the West of Bahia. In addition, there are not published studies investigating the relationship among rains, mosquito infestation and arboviral diseases in this region.

Anthropogenic factors were previously shown to affect the flow of genes involved in vector competence and insecticide resistance (Guagliardo et al., 2014). In this context, anthropogenic barriers were shown to influence dynamic of $A$. aegyptipopulations in a short-distance scenario (Hemme et al., 2010). Therefore, we hypothesized that a Federal 
Highway crossing a city could segregate populations of arbovirus vectors. In addition, we also asked if the river, which crosses the urban area, could also affect dispersion of mosquitoes. The geometric morphometrics of wings (GM) is an important tool in evaluating population diversity (Lorenz et al., 2017). Although wing variations detected by GM with regard to evolutionary rates are not always equivalent to those found using molecular markers (Vicente et al., 2011; Demirci et al., 2012), wing geometry has proven to be a powerful tool to detect intraspecific variability. In addition, it has been shown to be a satisfactory approach to preliminarily estimate population genetics (Lorenz et al., 2014, 2017; Vidal et al., 2012; Louise et al., 2015).

In this study, to test the hypothesis of the vector population distribution be influenced by the highway, we assessed its wing geometry and then checked for any population structure. Moreover, we tested the correlation between rainfall regime, mosquito infestation and arboviral disease cases in the city.

\section{Materials and methods}

Aim and specific aims

In this study, we aimed to understand the dynamics of mosquito vectors and arboviral diseases in Barreiras. Specific aims were: i) to understand the influence of both, a highway and a river on the distribution and variability of $A$. aegypti in the urban area of Barreiras and ii), to investigate the relationship among rains, mosquito infestation and arboviral diseases in the city.

Surveillance of building infestation index

We used secondary data regarding building infestation index (BII), which was raised and provided by the Center of Control of Zoonotic and Endemic Diseases of Barreiras, Brazil. BII was obtained by using the LIRAa method from January 2016 to September 2017 in Barreiras, as previously described (Lagrotta et al., 2008). In brief, the methodology includes the division of municipalities into strata defined according to the number of buildings, in blocks regardless of the neighborhood boundaries. Thus, the blocks receive a sequential numbering by neighborhood assigned by the vector control personnel, and each stratum consists of a minimum of 8,100 and a maximum of 12 thousand buildings.

\section{Surveillance of precipitation}

The pluviometric indexes were obtained on the electronic site of the National Institute of Meteorology, Brazil (INMET) (http://www. inmet.gov.br), from January 2016 to September 2017.

\section{Notifications of aggravations by arboviruses}

Secondary data regarding notifications of arboviral diseases aggravations were ceded by the Epidemiological Surveillance service of Barreiras.

\section{Statistical analysis}

For statistical analysis of the surveillance of building infestation index, surveillance of precipitation and notifications of aggravations by arboviruses, the data set was subjected to outlier verification (Grubbs test), and tested for normality and homogeneity of variance by using Shapiro-Wilk $W$ and Levene's tests, respectively. The data set underwent $\log$ and square root transformation for analysis and, subjected to Spermann correlation analysis. The probability of significance was set at $\alpha<0.05$ and all statistical analyses were performed in STATISTICA ${ }^{\circledR}$ version 8.0 .

\section{Sampling of A. aegypti larvae in urban area of Barreiras}

A. aegypti larvae were collected within the urban breeding sites of Barreiras. Four collection areas were defined considering the Rio Grande river and the BR242 Federal Highway as possible barriers, as shown in Fig. 1. Collection areas were defined as A, B and C. Larvae were collected in residences within sampling areas according to the LIRAa method, from November 2016 to March 2017.

\section{Development of larvae of A. aegypti in laboratory}

Larvae and pupae were placed in plastic containers containing water from natural mosquito breeding sites. Wings from emerged adult females were used to carry out geometric morphometrics (GM), as previously described (Louise et al., 2015). We sampled 21, 31, 16, female mosquitoes from A, B and C areas, respectively, for the GM analyses.

Preparation of mosquito wings for GM

Microscopy slides containing mosquito wings for GM were prepared as previously described (Louise et al., 2015). In brief, right wings of each individual were removed from the thorax and placed on microscopic glass slides with Canada balsam solution and covered with coverslips. Left wings were used when the right wing was damaged. Images of the wings were captured by Leica S6 stereoscopic microscope equipped with plain lenses. The coordinates of 18 landmarks represented by vein intersections were obtained using TpsDig v. 1.4 software (Fig. 2).

\section{Morphometric analysis}

Wing shape was determined in populations of $A$. aegypti from different areas. For morphometric analyses we removed the allometric effect. The generalised Procrustes superimposition was used to produce shape variables, as previously described (Vidal et al., 2012). Dissimilarity in wing shape among populations was determined by discriminant analysis in a morphospace of canonical variables using MorphoJ software. Discriminant analyses also allowed us to calculate the Mahalanobis distances (MD) among areas. Such distances were compared by nonparametric permutation tests (10,000 randomizations) using MorphoJ software. To test for dissimilarity of mosquitoes from sampling areas a reclassification test was carried out according to individuals' similarity to each area using MD.

\section{Results}

The dynamics of arboviral diseases and its relationship with precipitation and building infestation index (BII) were expected to involve correlation. Barreiras has a dry climate with well-defined rainfall seasons. This situation was observed from July to August 2016 and from June to September 2017, when there was no record of rain in the city (Fig. 3A). In general, notification of arboviral diseases decreases in the dry seasons. Thus, we hypothesized that rains were necessary to induce development of mosquitoes and then transmission of diseases. Spearman correlation analysis indicated strong and positive 


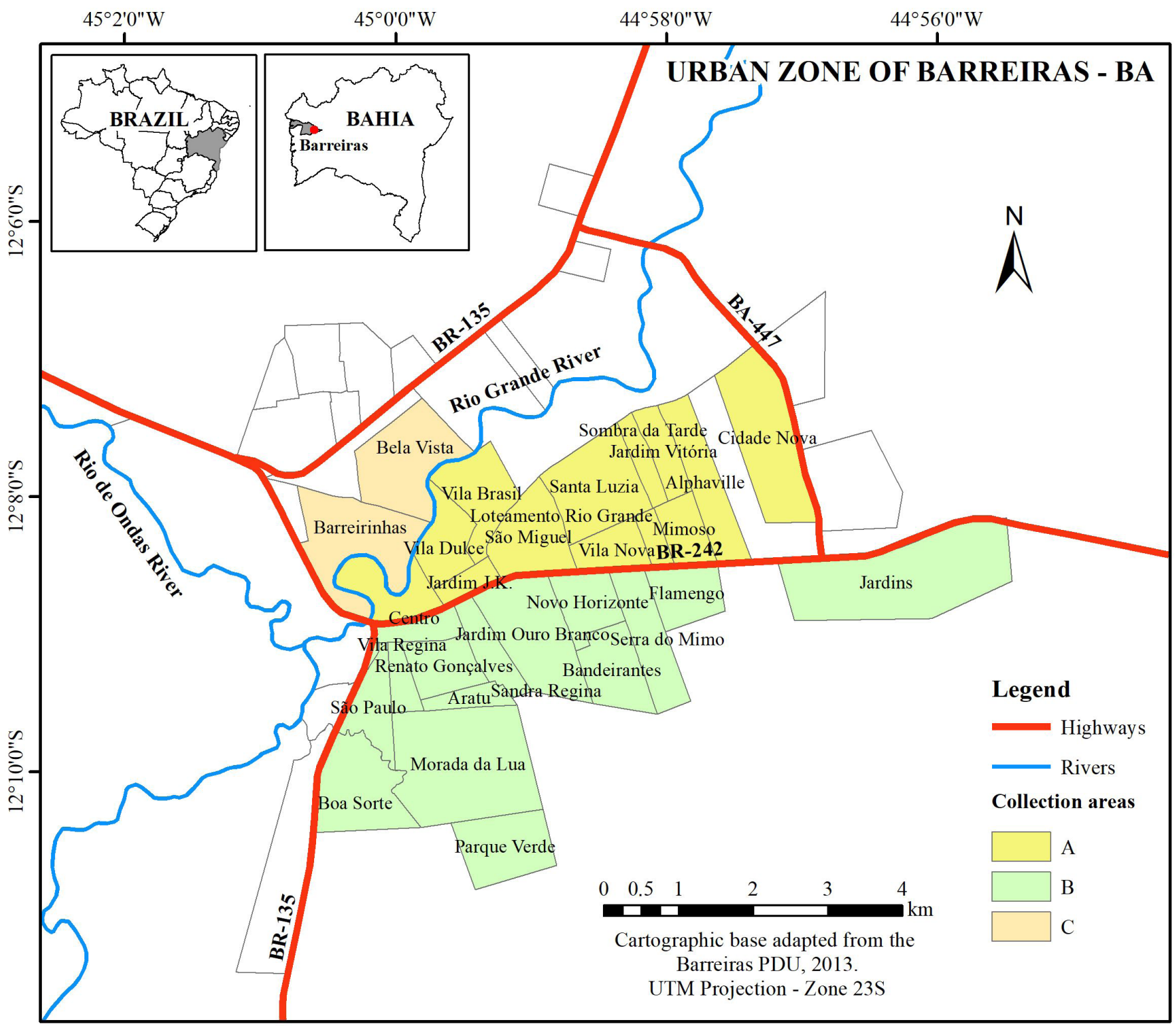

Figure 1 Sampling strategy in the urban area of Barreiras, Bahia, Brazil. The city is crossed by the Federal BR-242 Highway and by the Rio Grande River. Collection areas A, B and C were defined according to anthropic (highway) and natural (river) barriers.

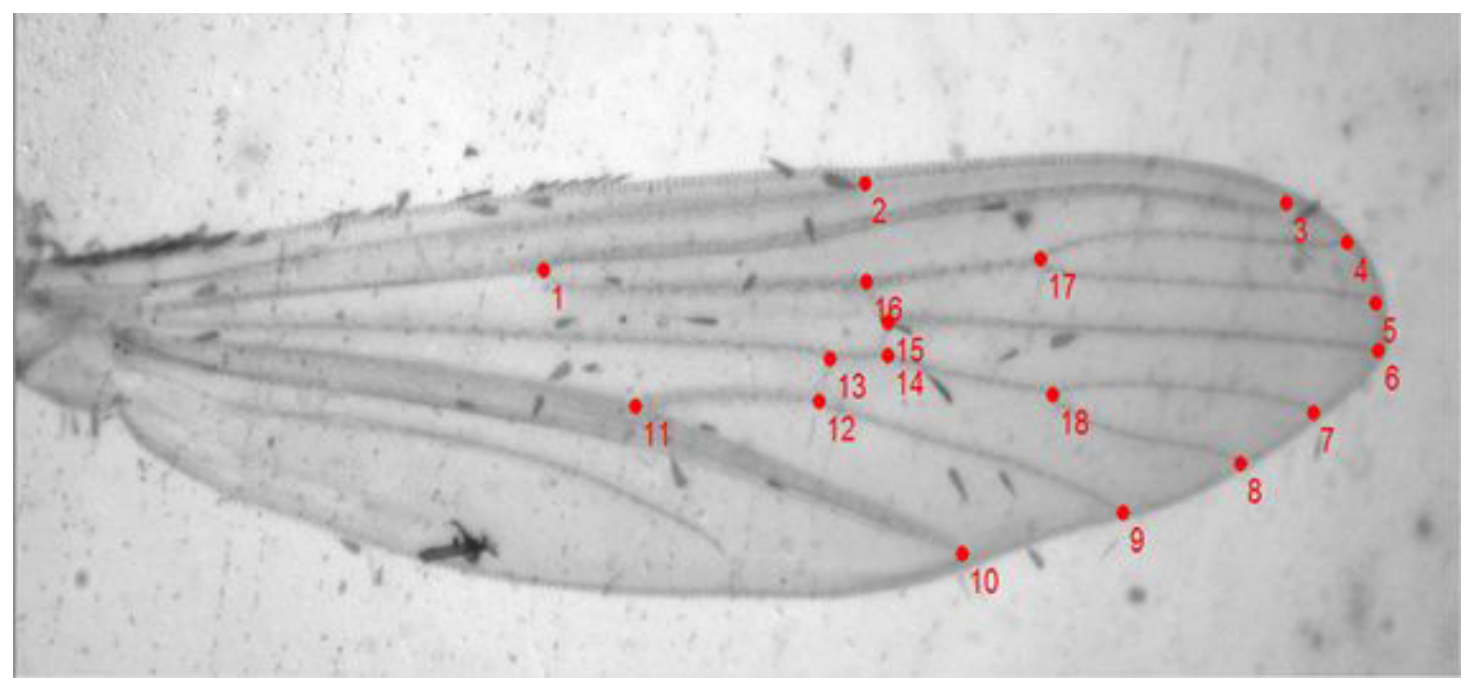



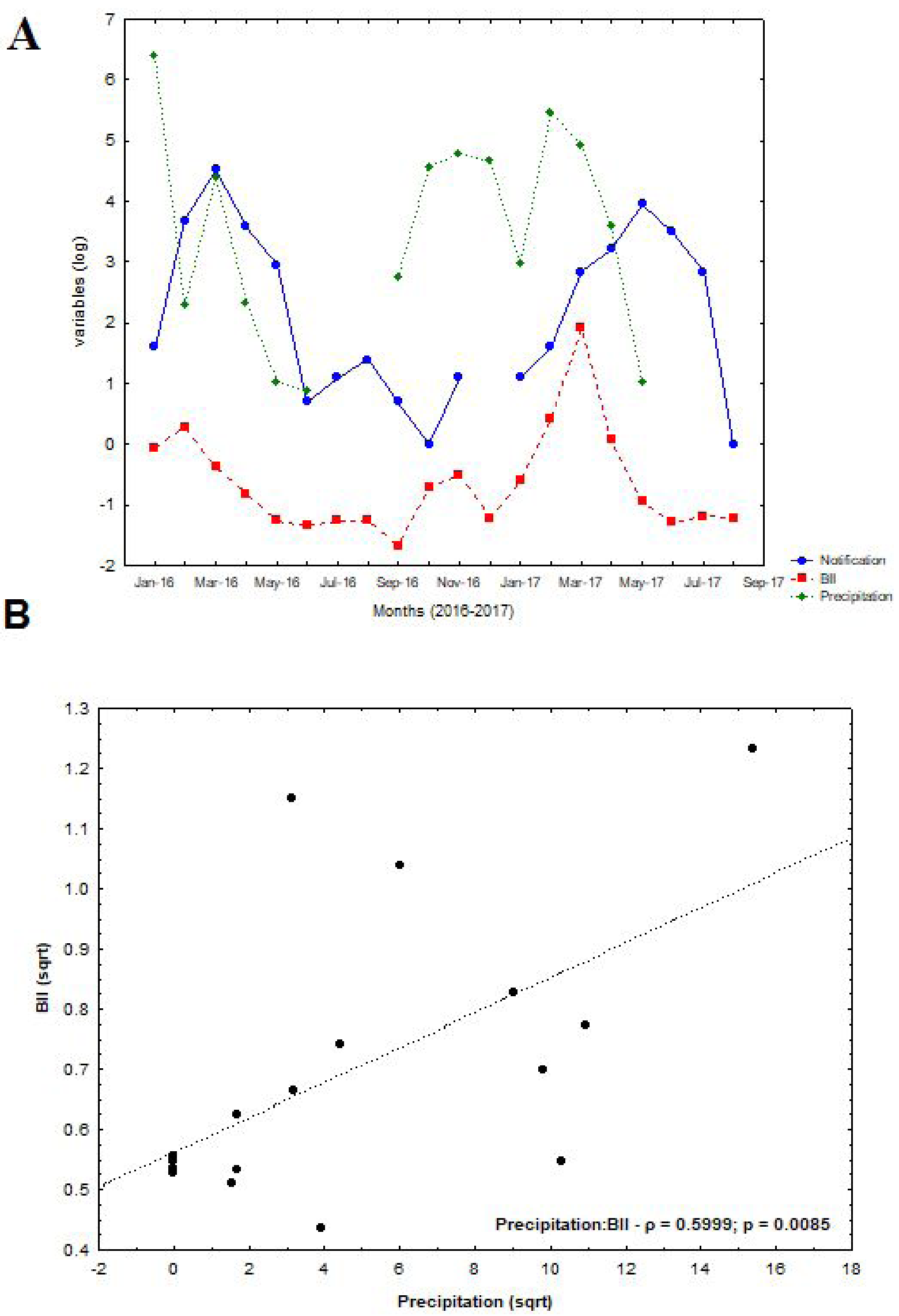

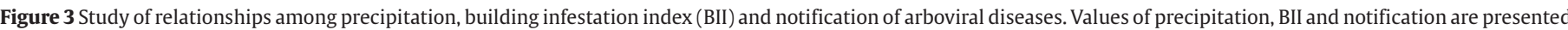

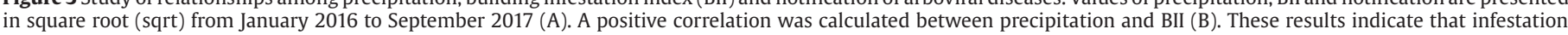
occurs in rain-dependent cycles. 
correlation between BII and precipitation ( $\rho=0.5999 ; \mathrm{p}=0.0085)$, i.e. when precipitation increases, building infestation also increases (Fig. 3B). The variables distribution during the evaluated period also suggest that after BII increasing, the number of notifications of arboviral diseases rises (Fig. 3A).

We also hypothesized that the BR242 Federal Highway and the Rio Grande river segregate populations of $A$. aegyptiin the city. Thus, we carried out geometric morphometrics $(\mathrm{GM})$ in order to compare populations of $\mathrm{A}, \mathrm{B}$ and $\mathrm{C}$ sampling areas. After removal of allometry, mosquitoes from the three sampling areas were shown to be morphometrically distinct when only the highway (Fig. 4A), only the river (Fig. 4B) or both (Fig. 4C) (highway and river) were considered as barriers. In addition, morphological space of $1^{\text {st }}$ and $2^{\text {nd }}$ canonical variables derived from wing shape comparison among A, B and C areas (Fig. 5) also indicated large divergence among populations.

Classification of individuals of different areas based on the Mahalanobis distances was $100 \%$ accurate for all the areas before validation. Scores of reclassification tests were ranged from $54.8 \%$ to $90 \%$ after validations. UPGMA phenograms using the Mahalanobis distance between areas indicated $A$ and $B$ as the most similar areas. The areas $A$ and $C$ were the more divergent, as shown in Fig. 6. All pairwise comparisons among the areas exhibited significant metric disparity ( $\mathrm{p}<0.0001$; permutation test). Together, our results indicate that both, the highway and the river, segregate mosquitoes from the studied areas.
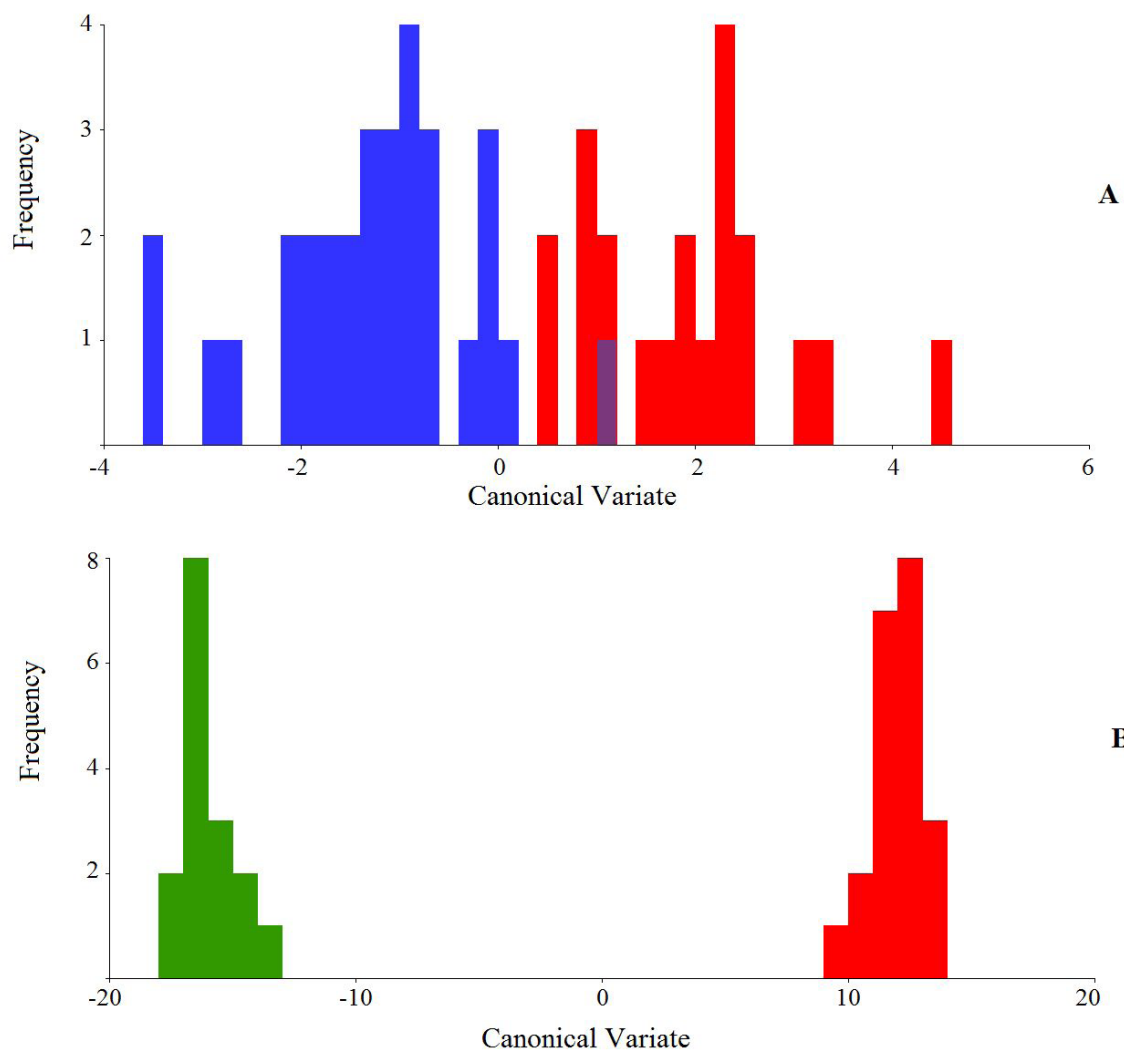

A )

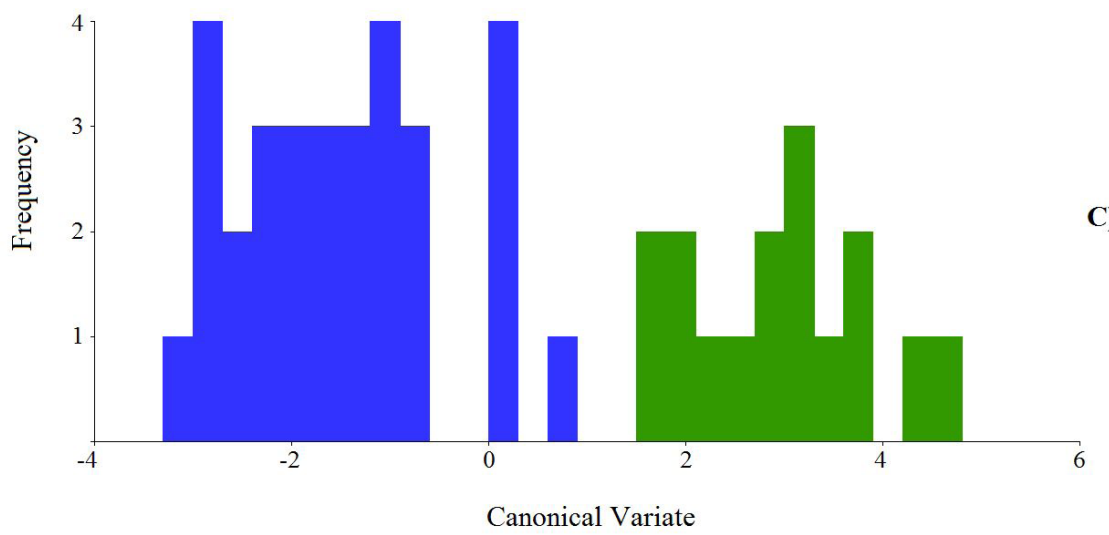

Area A

Area B

Area C

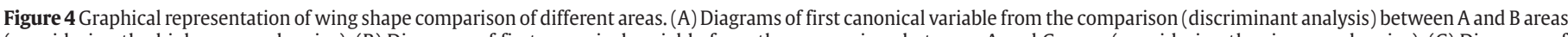

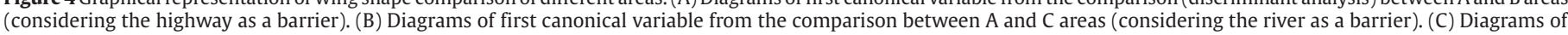
first canonical variable of the comparison between $\mathrm{B}$ and $\mathrm{C}$ areas (considering both, the highway and the river as barriers). 


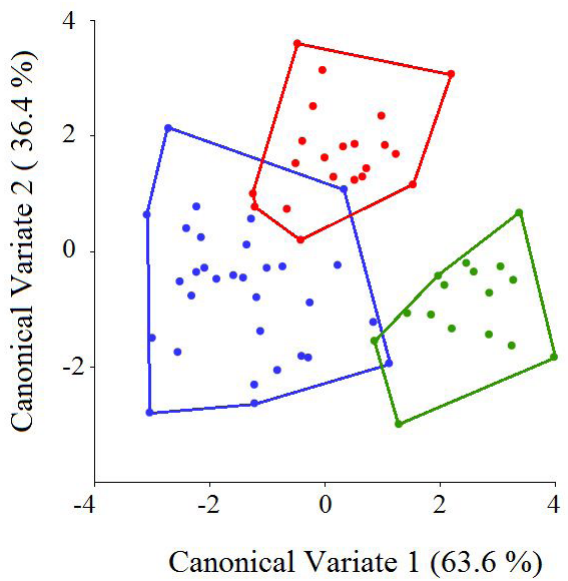

Figure 5 Morphological space of $1^{\text {st }}$ and $2^{\text {nd }}$ canonical variates derived from wing shape comparison (discriminant analysis) among A, B and C areas. Contribution of each Canonical Variation is indicated between brackets. Red, blue and green dots represent populations of $\mathrm{A}, \mathrm{B}$ and $\mathrm{C}$ areas, respectively.

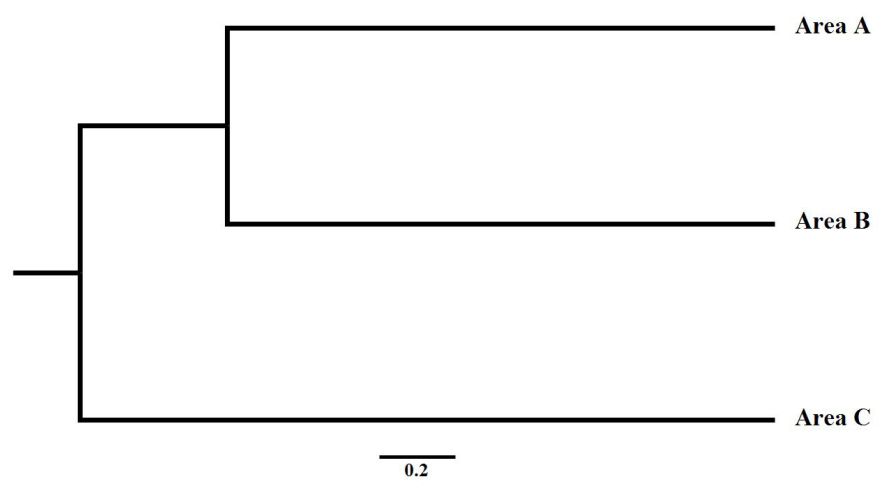

Figure 6 UPGMA phenograms using the Mahalanobis distance among the diferent areas describing shape divergences. All distances were significant $(\mathrm{p}<0.0001)$.

\section{Discussion}

Aedes aegypti ( $A$. aegypti) transmits arboviral diseases of high public health importance, including those caused by Zika virus(ZIKV), Dengue virus (DENV) and Yellow fever virus (YFV). It is estimated that 400 million people are infected annually by DENV. Recently, Zika virus (ZIKV), a emergent pathogen previously associated with mild infections, caused microcephaly in newborns and Guillain-Barré syndrome in Brazil ("Areas with Zika | Zika virus | CDC," ; Calvet et al., 2016; Wikan and Smith, 2016). In addition, Yellow fever virus (YFV) is causing an important outbreak in Brazil (Gómez et al., 2018; Moreira-Soto et al., 2018). Controlling arthropod vectors is the most effective method to prevent epidemics of major arboviral diseases. However, control programs will fail with lack of information regarding dynamics of both, arboviral diseases and their vectors. In this study, we investigated the relationship among precipitation, building infestation index (BII) and arboviral diseases in Barreiras, Brazil. In addition, we evaluated the influence of both, a highway and a river on the distribution and variability of $A$. aegypti in the urban area of the city.

As indicated by results regarding the relationship among rains, BII and notifications of arboviral diseases, infestation occurs in rain-dependent cycles. As rainy and dry seasons alternate turns in Barreiras, it is clear that mosquito eggs have a high capacity to keep viable during the dry season. Thus, it is necessary to tackle potential breeding sites even in the dry season. For example, chemicals capable of controlling development of larvae could be applied in dry containers during dry seasons. Our results are in accordance with reported relationships among climate, $A$. aegypti infestation and arboviral diseases (Dibo et al., 2008; Wee et al., 2013; Silva et al., 2016).

Barreiras is crossed by both, a Federal Highway and a river. It is a very common geographical feature for Brazilian cities. We hypothesized that the highway and the river are barriers capable of segregating populations of $A$. aegyptiin areas limited by them. Natural barriers were previously shown to restrict gene flow among $A$. aegypti populations (Lozano-Fuentes et al., 2009). In addition, urban landscapes were also shown to influence population dynamics of mosquito vectors (Hemme et al., 2010). Now, we show that both, natural and anthropic barriers are able to segregate mosquito population in a same city. It means that distinct populations with low (or absent) gene flow in a given city may respond differently to a control strategy. Control method to all areas of a given city crossed by barriers is a risky strategy. For example, segregated and distinct population can respond differently to the use of a same insecticide. This is a relevant observation with regard to the design of vector control programs. As far as we know, this is the first report showing that both, natural and anthropic barriers are able to influence $A$. aegypti dynamics in the same urban area.

We conclude that results presented in this study should be used as a reference to better design vector control strategies in cities with similar geographical characteristics to those of Barreiras.

\section{Acknowledgements}

We appreciate the financial support of the International Society for Infectious Diseases, Fundação de Amparo à Pesquisa do Estado da Bahia (FAPESB) (PET 0024/2016) and Conselho Nacional de Desenvolvimento Científico e Tecnológico (CNPq), Grant \# 311805/2014-0. We are thankful to FAPESB by providing undergraduate research fellowship for Danielle Beatriz Marques Campos Arcanjo. We are also thankful to the support of Center of Control of Zoonotic and Endemic Diseases of Barreiras, Bahia, Brazil. We are thankful to Karina Zanatta and Fernanda Almeida Lopes for technical assistance.

\section{Conflicts of interest}

The authors declare no conflicts of interest.

\section{Author contribution statement}

DBMCA, POV, JYGS, LPRV, LS and JHA conceived the study. DBMCA, POV, LPRV, LS and JHA carried out sampling of $A$. aegypti larvae in urban area of Barreiras and laboratory work. DBMCA, POV, JYGS, LPRV and JHA collected and analyzed data regarding building infestation index, precipitation and notifications of aggravations by arboviruses. All authors have approved the final article.

\section{References}

Calvet, G., Aguiar, R. S., Melo, A. S. O., Sampaio, S. A., Filippis, I., Fabri, A., Araujo, E. S. M., Sequeira, P. C., de Mendonça, M. C. L., Oliveira, L., Tschoeke, D. A., Schrago, C. G., Thompson, F. L., Brasil, P., Santos, F. B., Nogueira, R. M. R., Tanuri, A., Filippis, A. M. B., 2016. Detection and sequencing of Zika virus from amniotic fluid of fetuses with microcephaly in Brazil: a case study. Lancet Infect. Dis. 16 (6), 653660. https://doi.org/10.1016/S1473-3099(16)00095-5.

Centers for Disease Control and Prevention, 2016. Zika virus. Available in: http://www.cdc.gov/zika/geo/ (accessed 15 March 2016). 
Centers for Disease Control and Prevention, 2017. Zika virus: Transmission. Available in: https://www.cdc.gov/zika/transmission/index.html (accessed 1 December 2017).

Demirci, B., Lee, Y., Lanzaro, G. C., Alten, B., 2012. Altitudinal genetic and morphometric variation among populations of Culex theileri Theobald (Diptera: Culicidae) from northeastern Turkey. J. Vector Ecol. 37 (1), 197-209. https://doi.org/10.1111/j.1948-7134.2012.00217.x.

Dibo, M. R., Chierotti, A. P., Ferrari, M. S., Mendonça, A. L., Chiaravalloti Neto, F., 2008. Study of the relationship between Aedes (Stegomyia) aegypti egg and adult densities, dengue fever and climate in Mirassol, state of São Paulo, Brazil. Mem. Inst. Oswaldo Cruz 103 (6), 554-560. https://doi.org/10.1590/S0074-02762008000600008.

Gómez, M. M., Abreu, F. V. S., Santos, A. A. C., Mello, I. S., Santos, M. P., Ribeiro, I. P., Ferreira-de-Brito, A., Miranda, R. M., Castro, M. G., Ribeiro, M. S., Laterrière Junior, R. C., Aguiar, S. F., Meira, G. L. S., Antunes, D., Torres, P. H. M., Mir, D., Vicente, A. C. P., Guimarães, A. C. R., Caffarena, E. R., Bello, G., Lourenço-de-Oliveira, R., Bonaldo, M. C., 2018. Genomic and structural features of the yellow fever virus from the 2016-2017 Brazilian outbreak. J. Gen. Virol. 99 (4), 536-548. https://doi.org/10.1099/jgv.0.001033.

Guagliardo, S. A., Barboza, J. L., Morrison, A. C., Astete, H., VazquezProkopec, G., Kitron, U., 2014. Patterns of geographic expansion of Aedes aegypti in the Peruvian Amazon. PLoS Negl. Trop. Dis. 8 (8), 1-12. https://doi.org/10.1371/journal.pntd.0003033.

Hemme, R. R., Thomas, C. L., Chadee, D. D., Severson, D. W., 2010. Influence of urban landscapes on population dynamics in a shortdistance migrant mosquito: Evidence for the dengue vector Aedes aegypti. PLoS Negl. Trop. Dis. 4 (3), 1-9. https://doi.org/10.1371/ journal.pntd.0000634.

Lagrotta, M. T. F., Silva, W. C., Souza-Santos, R., 2008. Identification of key areas for Aedes aegypti control through geoprocessing in Nova Iguaçu, Rio de Janeiro State, Brazil. Cad. Saude Publica 24 (1), 70-80. https://doi.org/10.1590/S0102-311X2008000100007.

Lorenz, C., Almeida, F., Almeida-Lopes, F., Louise, C., Pereira, S. N., Petersen, V., Vidal, P. O., Virginio, F., Suesdek, L., 2017. Geometric morphometrics in mosquitoes: what has been measured? Infect. Genet. Evol.54, 205-215. https://doi.org/10.1016/j.meegid.2017.06.029.

Lorenz, C., Marques, T. C., Sallum, M. A. M., Suesdek, L., 2014. Altitudinal population structure and microevolution of the malaria vector Anopheles cruzii (Diptera: culicidae). Parasit. Vectors 7 (581), 1-12 https://doi.org/10.1186/s13071-014-0581-8.

Louise, C., Vidal, P. O., Suesdek, L., 2015. Microevolution of Aedes aegypti. PLoS One 10 (9), 1-16. https://doi.org/10.1371/journal.pone.0137851.
Lozano-Fuentes, S., Fernandez-Salas, I., Lourdes Munoz, M., Garcia-Rejon, J., Olson, K. E., Beaty, B. J., Black 4th, W. C., 2009. The neovolcanic axis is a barrier to gene flow among Aedes aegypti populations in Mexico that differ in vector competence for Dengue 2 virus. PLoS Negl. Trop. Dis. 3 (6), 1-10. https://doi.org/10.1371/journal. pntd.0000468.

Moreira-Soto, A., Torres, M. C., Lima de Mendonça, M. C., Mares-Guia, M. A., Santos Rodrigues, C. D., Fabri, A. A., dos Santos, C. C., Machado Araújo, E. S., Fischer, C., Ribeiro Nogueira, R. M., Drosten, C., Sequeira, P. C., Drexler, J. F., Bispo de Filippis, A. M., 2018. Evidence for multiple sylvatic transmission cycles during the 2016-2017 yellow fever virus outbreak, Brazil. Clin. Microbiol. Infect. 24 (9), 1019.e1-1019. e4. https://doi.org/10.1016/j.cmi.2018.01.026.

Pongsumpun, P., Garcia Lopez, D., Favier, C., Torres, L., Llosa, J., Dubois, M. a, 2008. Dynamics of dengue epidemics in urban contexts. Trop. Med. Int. Health 13 (9), 1180-1187. https://doi.org/10.1111/j.13653156.2008.02124.X.

Silva, F. D., Santos, A. M., Corrêa, R. G. C. F., Caldas, A. J. M., 2016. Temporal relationship between rainfall, temperature and occurrence of dengue cases in São Luís, Maranhão, Brazil. Cien. Saude Colet. 21 (2), 641-646. https://doi.org/10.1590/1413-81232015212.09592015.

Soper, F. L. 1967. Dynamics of Aedes aegypti distribution and density. Seasonal fluctuations in the Americas. Bull. World Health Organ. 36 (4), 536-538.

Vicente, J. L., Sousa, C. A., Alten, B., Caglar, S. S., Falcutá, E., Latorre, J. M., Toty, C., Barré, H., Demirci, B., Di Luca, M., Toma, L., Alves, R., Salgueiro, P., Silva, T. L., Bargues, M. D., Mas-Coma, S., Boccolini, D., Romi, R., Nicolescu, G., Rosário, V. E., Ozer, N., Fontenille, D., Pinto, J., 2011. Genetic and phenotypic variation of the malaria vector Anopheles atroparvus in southern Europe. Malar. J. 10 (5), 1-9. https://doi.org/10.1186/1475-2875-10-5.

Vidal, P. O., Carvalho, E., Suesdek, L., 2012. Temporal variation of wing geometry in Aedes albopictus. Mem. Inst. Oswaldo Cruz 107 (8), 1030-1034. https://doi.org/10.1590/S0074-02762012000800011.

Wee, L. K., Weng, S. N., Raduan, N., Wah, S. K., Ming, W. H., Shi, C. H., Rambli, F., Ahok, C. J., Marlina, S., Ahmad, N. W., Mckemy, A., Vasan, S. S., Lim, L. H., 2013. Relationship between rainfall and Aedes larval population at two insular sites in Pulau Ketam, Selangor, Malaysia. Southeast Asian J. Trop. Med. Public Health 44, 157-166.

Wikan, N., Smith, D. R., 2016. Zika virus: history of a newly emerging arbovirus. Lancet Infect. Dis. 16 (7), e119-e126. https://doi.org/10.1016/ S1473-3099(16)30010-X. 